\title{
Notas sobre educação popular a partir da pesquisa com recicladoras e recicladores
}

Lousada, Vinícius Lima ${ }^{1}$

\author{
falar a palavra certa, \\ a palavra que atua, \\ a palavra que transforma \\ é já começar a transformar \\ Paulo Freire
}

\section{Resumo}

Procurei nomear este artigo de "notas" porque pretendo trazer à baila algumas das minhas anotações a respeito das aprendizagens efetivadas com recicladoras e recicladores da Associação de Reciclagem Ecológica Rubem Berta (Galpão), em Porto Alegre/RS. Ressalto a palavra "recicladora" no feminino e no plural, como também, à frente na ordem da palavra "reciclador" não por mero jogo de palavras ou simples gentileza. Trata-se de uma tentativa sincera, embora reconhecidamente tímida, de homenagear essas mulheres que tenho acompanhado como educador e pesquisador

Educação Popular. Recicladoras. Recicladores

\section{Resumen}

Traté de nombrar este artículo de "notas" porque quiero evidenciar algunas de mis anotaciones al respecto de los aprendizajes realizados con recicladoras y recicladores de la Associação de Reciclagem Ecológica Rubem Berta (Galpão), en Porto Alegre / RS. Subrayo la palabra "recicladoras" en femenino y plural, como también por delante en el orden de la palabra "reciclador" no por mero juego de palabras o simple gentileza. Se trata de un intento sincero, aunque reconocidamente tímido, de honrar a estas mujeres que he seguido como educador e investigador.

Educación Popular. Recicladoras. Recicladores

1 Doutor em Educação, professor e coordenador da Licenciatura em Pedagogia do Instituto Federal do Rio Grande do Sul, IFRS. http://www.bento.ifrs.edu.br/site/ 


\section{INTRODUÇÃO}

Acompanho aqui a recusa freireana de qualquer forma de manifestação machista ou discriminatória, inclusive no campo da linguagem. Do mesmo modo, é preciso dizer que são essas Marizas, Tânias, Nairs, Adrianas, Gilmaras, Jumaras, Simones e outras oprimidas não somente na dimensão da pobreza a que são submetidas, num recorte local das consequências funestas globais do darwinismo social instaurado nos dias que vivemos, mas também pela cultura predominantemente machista presente, seja na tradição judaico-cristã, seja no modus vivendi "microterritório" do Galpão, onde os homens que são minoria se impõem e ao reproduzirem essa sócio-ilógica.

Essas mulheres que fazem a vida do Galpão enfrentam no cotidiano o duro labor braçal que afeta a sensibilidade, que marca suas horas no ritmo de produção reinventado no diálogo nas mesas de triagem, com suas piadas, deboches e mesmo suas brigas.

É na triagem dos materiais recicláveis do lixo - com seus odores e sujeiras - que chega à unidade de reciclagem, não raramente entre fezes alheias e alimentos embolorados, das sobras mesmo, que elas materializam o seu trabalho e geram solidariamente e individualmente a sua renda, obviamente, não numa solidariedade dos anjos, perfeita ou idealizada. E sim, na solidariedade possível que essas formas de inclusão precária que o trabalho com o refugo da sociedade de consumo permite.

\section{Recicladoras no feminino e no plural}

Em minhas observações participantes junto a essas mulheres não é difícil perceber o que um dos pesquisadores de nosso grupo nomeou de garimpo, ou seja, a coleta pessoal de material reciclável para a venda a terceiros fora da associação para remuneração pessoal, a despeito das intencionalidades de trabalho coletivo e colaborativo da associação.

Nas leituras das recicladoras o garimpo é a oportunidade de "fazer um dinheiro a mais para um leitinho, etc.". A necessidade material sobrepuja os 
discursos da economia solidária que não se materializam na totalidade nessa associação cooperativa criando uma tensão que faz do trabalho solidário uma busca solitária pela alimentação pessoal e dos seus, ou para algum pequeno luxo, uma compra de material de limpeza, higiene pessoal, cigarro ou leite, fora do orçamento normal nas classes subalternas da sociedade contemporânea.

Essas mulheres sentem nas carnes o peso das interdições a que são acometidas, são corpos conscientes interditados de ser, com o direito sobre si negado várias vezes ante a imposição dos homens com os quais convivem. Têm o direito de dizer a sua palavra roubada muitas vezes, mas não deixam de transgredir o silêncio que lhes é imposto pela dominação masculina reproduzida no recorte do Galpão.

Sua resistência se desdobra através de críticas "de bastidores", de sarcasmos reveladores e de uma justa raiva que manifestam como que afirmando sua presença no mundo, na denúncia do que é impróprio à vida humana ou à dignidade de mulher no ambiente de trabalho que se pressupõe solidário.

Corpos conscientes - repito - estigmatizados por lidarem com o lixo da sociedade do descarte e do consumo desvairado, identificadas por outras pessoas, que ignoram o seu trabalho, como se fossem menos gente ou refugo social cuja desumanização imposta pelo lidar com as sobras deveria, igualmente, reforçar uma autoimagem de ser menos.

Contudo, o aceite da coisificação não se dá de forma dócil e meramente reprodutiva do que se estabelece no âmbito global da sociedade de classes. É preciso ressaltar a capacidade de resiliência dessas mulheres que se refazerem ante as situações- limites que se Ihes estabelecem, transgredindo a feiura do cenário de trabalho com lixo com os seus próprios ajustes e enfeites corporais, seus vários anéis e bijuterias, que reafirmam a sua gentilidade que procura resistir à desumanização. Nesse grupo de recicladoras as mulheres parecem não ceder às divisões do eu e às interdições que o viver e o trabalhar na periferia impõem. Apesar de não poderem transitar livremente nos espaços da cidade, pela falta de recursos pecuniários para o transporte público, do controle de 
horários frente à insegurança da vila, da dominação masculina dos parceiros e dos desafios da educação dos filhos e da manutenção social, afetiva, econômica da família, todas eu, a seu modo não-padronizado, repito, apresentam uma capacidade de refazerem-se, de juntar os pedaços retomando a esperança e a fé na vida.

A categoria resiliência tem me ajudado a entender o fenômeno desse quefazer "manhoso" - no sentido das estratégias próprias de sobrevivência dos pobres. Entretanto, para não malbaratar a categoria de outro campo das Ciências Humanas é preciso considerar o que compreendo pela mesma. De fato, resiliência consiste numa imagem tomada da Física pela Psicologia. Com a colaboração dessa última podemos concebê-la como a capacidade do sujeito em lidar com problemas, superar as situações- limites e resistir à pressão das situações as mais adversas sem adentrar um surto psicótico. Entretanto, essa atitude de refazer-se é uma opção do indivíduo como sujeito de ocorrências que, ao saber-se inacabado e condicionado pelas materialidades da existência não se admite determinado por elas.

Nas redes de sociabilidade que se estabelecem, dentro e fora da Unidade de Reciclagem que estudo, destacam-se os encontros para o café, as trocas de confidências, a partilha de afetos e saberes que denotam a sabedoria popular que se elabora na leitura do mundo feita a partir do limite ou do abismo da sociedade desigualmente configurada no que toca ao acesso aos bens culturais, à educação e outras condições concretas da modernidade que não se realiza na periferia das grandes cidades.

\section{Da ação educativa e da entrada no Galpão de Reciclagem}

A Associação de Reciclagem Ecológica Rubem Berta é existente desde o ano de 1993, e foi gerada como parte de um "macroprojeto" da Prefeitura Municipal de Porto Alegre de reassentamento urbano apartado das denominadas zonas de risco da Capital, articulando a questão da moradia e da geração de renda. A população que vivia nos arredores do muro que separava 
a Avenida Sertório dos arredores do Aeroporto Salgado Filho e dava conta da sobrevivência a partir da relação com o lixo foi transferida para a Zona Norte da cidade, nas proximidades do Conjunto Habitacional Rubem Berta. A construção das casas se deu de forma "germinal" com a possibilidade de inserção de outras peças conforme as formas de apropriação e as necessidades dos residentes.

$\mathrm{Na}$ atualidade, contando com trinta associados, a A. R. E. Rubem Berta se mantém com o auxílio econômico do Departamento Municipal de Limpeza Urbana da Cidade de Porto Alegre, e com o produto das vendas de material reciclável, separado e classificado conforme a sua natureza, para clientes fixos e outros alternados, permitindo assim a manutenção da partilha dos recursos econômicos obtidos para fins de pagamento de salários aos associados conforme as horas trabalhadas. Foi nesse cenário atuei como coordenador pedagógico no Projeto "Reciclando Vida", em 2007, e estou presente enquanto pesquisador e assessoria na referida associação desde então.

Sair do binário na investigação social, lidar com ambiguidades e saber ouvir "manhas", transitar entre as tramas do cotidiano do galpão e compreender uma rede de significados tecida na periferia de Porto Alegre para mim, educador advindo do interior do Rio Grande do Sul com inserções em periferias urbanas de contextos diferentes, se constitui num belo processo educativo no que se refere à minha formação enquanto gente, pesquisador e doutorando.

Quando me referi às "manhas" no acima, estou me reportando ao que Freire (2006), fornecendo-nos uma compreensão mais rigorosa do ponto de vista da interpretação da cultura popular, assim nomeia os aprendizados dos oprimidos que fomentam, na sua práxis existencial, uma cultura da resistência. A resistência presente na aparente adequação à situação-limite consistiria, assim, numa atitude de rebeldia. Ainda, da produção freireana (Freire, 2003) colho a concepção de situação- limite como toda aquela circunstância presente na vida dos sujeitos que os impedem de serem mais, de darem vazão a essa vocação inerente à condição humana bem caracterizada pelo inacabamento. As situações-limites são situações de opressão articuladas com um projeto social anti-dialógico que, a serviço da dominação de grupos sociais privilegiados em 
relação aos esfarrapados do mundo, produzem a desumanização de quem oprime e de quem é oprimido, exigindo, destes últimos, atitudes- limites, de ruptura paulatina com o projeto de opressão mediante ações reflexivas que transcendam as situações-limites.

Sem, contudo, contarmos com uma concepção antropológica que abarque o inacabamento, ou a incompletude e a história como tempo de possibilidade, é impossível pensar/agir no sentido de superação das situações-limites. Incompletude é uma categoria de pensamento que pode ser compreendida com a contribuição de Paulo Freire quando nos fala da consciência do inacabamento, ou seja, trata- se do ator social saber-se como ser em processo de construção, como um projeto que se refaz ao longo de seu trajeto histórico, condicionado pelos fatores que marcam seu contexto, mas portador de uma vocação ontológica de ser mais, ou seja, um processo de dinâmica transformação e ampliação de suas possibilidades durante a existência.

O reconhecimento do próprio inacabamento permite ao sujeito predisporse à mudança, ao novo, ao diferente, a começar pelo exercício da autocrítica, admitindo em si a carência de saberes e valores que o autorizariam a apreender a realidade ou o objeto de estudo na sua inteireza. Para Freire, "o inacabamento do ser ou a sua inconclusão é própria da experiência vital. Onde há vida há inacabamento. " (FREIRE, 2000, p. 55). Somos seres de circunstâncias transitórias, modificadas pela nossa capacidade de intervir no mundo, fazê-lo e modificá-lo e, concomitantemente, modificarmo-nos e fazermo-nos gente, quer dizer, humanizarmo-nos. Não somos simplesmente homo sapiens, sapiens porque vivemos na condição dessa espécie, somos porque estamos sendo, damos significado à vida transformando-a em existência.

Finalmente, gostaria de ressaltar que a não-linearidade de suas trajetórias e a manifestação plural do perfil identitário das mulheres recicladoras que estudo pede um tipo de análise sociológica que não se presta ao mero ajuste dos dados colhidos no campo empírico aos referenciais teóricos estudados. O recorte social desse grupo manifesta plenamente a complexidade desses dias que coloca em 
cheque as análises sociais tradicionais, exatamente como ressalta Melucci (2001) em seus escritos sobre a invenção social do presente.

\section{Café, pão com linguiça, diálogo e alteridade}

Gostaria ainda de tecer breve consideração sobre o café no galpão. Esse hábito se reveste de um caráter ritualístico e simbólico. Tem o seu horário religiosamente obedecido por todas e todos, jamais sendo interrompido na chegada de autoridades, visitas ou descarga de material. Alguns preparam pães, bolinhos, polenta com salsicha e partilham entre si. Outros juntam trocados para comprar o pão, manteiga, linguiça, etc. Formam pequenos grupos livremente seguindo o critério de afinidades entre leituras de mundo, gostos, crenças e humores, aliás, muita coisa é regida pelo estado de humor no Galpão. Esses grupos se localizam em diferentes áreas conforme o bem-querer, fenômeno que se reflete até na disposição da ordem de pessoas nas mesas de triagem.

Explorei bastante esse espaço de convivência para a minha inserção e legitimidade junto ao grupo. Quando observo e participo do café, onde sempre me oferecem algo, mesmo que eu não tenha trazido nada, percebo que desfilam diálogos sobre os cuidados com os filhos, a luta por ampliar a casa germinada para atender melhor a família, as novidades do Galpão e da comunidade, trocas simbólicas sobre crenças religiosas, partilhas de receitas de chás e vivências junto ao posto médico, entre outros temas que emergem e que não cabe agora elencar.

Fica evidente que o que articula as pessoas no seu trabalho e em nossas ações educativas é, fundamentalmente, o elemento afetivo, a confiança que nasce por meio do diálogo entre os pares, numa relação de mútuo respeito e horizontalidade algumas vezes. Aliás, a respeito do diálogo, elucida-nos Freire (2006, p. 120) de que enquanto relação democrática, "o diálogo é a possibilidade de que disponho de, abrindo-me ao pensar dos outros, não fenecer no isolamento. " Assim, a busca do outro denota a formação de uma parceria, de 
uma rede de relação que livra aquele que procura o outro na ação dialógica do individualismo doentio e da desumanização por ele gerado.

Nessa perspectiva, o educador da esperança não deixa de ressaltar 0 diálogo intersubjetivo como uma relação horizontal entre $\mathrm{A}$ e $\mathrm{B}$, oriundo de uma matriz crítica, provavelmente intuída pelos oprimidos - penso eu - frente ao esgotamento do anti- diálogo e à desertificação afetiva edificada na lógica social que ora o reforça. $O$ diálogo se nutre do amor, de humanidade, de esperança, de fé e de confiança recíproca que se estabelece na ação comunicativa entre os sujeitos do diálogo. E como recorda Freire: "quando os dois polos do diálogo se ligam assim, com amor, com esperança, com fé no próximo, se fazem críticos na procura de algo e se produz uma relação de empatia entre ambos" (1979, p. 39). Desse modo, o diálogo autêntico se fundamenta e se nutre do amor, da aposta na relação com o outro.

Essa aposta pede uma abertura à alteridade, uma categoria teórica apresentada no âmbito da Filosofia da Libertação. Essa categoria se inscreve numa concepção filosófica, como a de Enrique Dussel, em que o ser é o Outro (ZIMMERMAN 1987, p. 44), totalmente o outro, não como extensão de mim porque distinto e externo a mim mesmo e ao meu mundo simbólico, mas, como um sujeito cujo mistério preciso abrir-me para que a nossa relação não seja de dominação e, por consequência, de opressão; propondo, assim, a superação dos valores auto afirmativos que imperam na racionalidade presente na modernidade ocidental.

Esse conceito fundamental em Dussel, a alteridade, pautado na anterioridade antropológica, cara também a Freire (2007, p. 30) que lembra no âmbito da relação pedagógica a necessidade do respeito aos saberes "socialmente construídos na prática comunitária" do outro (o educando), referindo-se mesmo às aprendizagens que os sujeitos trazem anteriormente ao diálogo com o educador, construídas na práxis, existencial, com os outros e no mundo. Esses saberes, aprendizagens, elementos culturais e simbólicos se configuram, sob encaminhamentos de suas escolhas, em elementos da identidade própria do outro. 
A alteridade caracteriza-se, segundo Dussel, na "passagem diacrônica, desde o ouvir a palavra do outro até a adequada interpretação" (1986, p. 208) orientada por uma ética antropológica coerente. Nesse sentido, estabelecer uma relação alteritária com o outro exige aprender a ouvi-lo, não apenas subsumindoo em sua totalidade, mas compreendendo-o após uma temporalidade diacrônica. A palavra do outro é escutada e assumida na aceitação da identidade do outro.

Ouvir não é fazer-se objeto passivo da fala do outro, embora a necessidade fundamental do silêncio, mas sim uma postura de escutar como sujeito coparticipe do ato comunicativo, adentrando com o outro no movimento interno de seu pensamento que, por sua vez, metamorfoseia-se em linguagem. Assim, saber ouvir é o que torna possível a comunicação entre os sujeitos. E, dessa forma, ouvir implicaria numa disponibilidade permanente do sujeito que ouve à fala do outro, abrindo-se a esta, ao gesto e à identidade própria do outro que faz uso da palavra. Aquele que ouve não se anula, não é mero objeto da exposição alheia, ao contrário disso, participa do ato dialógico exercitando, inclusive, o direito democrático de discordar, de opor-se e tomar posição ante a palavra exposta pelo outro.

Nesse "entrevero simbólico" observo a tentativa dessas mulheres em nem sempre classificarem seus pares, de os nomearem a priori, buscando, ante as identidades que se refazem na ecologia de suas relações sociais e na tessitura de seus itinerários, em que o Outro: o pobre, o excluído e marginalizado, a mulher; enfim, os que têm o direito de dizer a sua palavra negados, sejam plenamente incluídos. Admitir a outredade daqueles com os quais interagem. "Fulana não é uma drogada", afirmam, "ela tem uns probleminhas com um fumo mais pesado, mas é excelente pessoa quando não tá chapada".

Outras vezes, quando convém, o grupo lança mão da estigmatização: "Ela bebe demais, é estourada, por isso não serve para estar na coordenação". Esse tipo de fala aparece quando uma das associadas que já foi uma liderança na comunidade ensaia uma forma possível de empoderamento e critica o modus operandi do Galpão, colocando em dúvida o status quo da liderança masculina, 
ausente no concreto do trabalho cotidiano, e daqueles que nela aconchegam ora recolhendo proteção pessoal, ora efetivando a manutenção da sobrevivência ou do poder conferido aos que pertencem de alguma forma ao colegiado de direção.

\section{Educação Popular: breve ideário e a crítica saudável}

Consolidado nos anos 70 e 80 o trabalho social e educativo denominado Educação Popular, as mais diversas experiências geraram alternativas educativas, políticas e culturais para que as classes populares tentassem superar as questões originadas nas situações de opressão e exclusão social em diferentes pontos da América Latina, com o engajamento de educadores e diferentes profissionais cuja opção parecia ser um projeto de libertação dos pobres.

A educação se configura como popular quando a sua opção se define pelo popular, ou seja, no momento em que a ação pedagógica assume tal sentido em sua intencionalidade e prática que se manifesta em plena sintonia com os interesses das classes populares. Uma prática educativa é genuinamente popular no momento em que está engajada na luta da participação social e no projeto de construção da cidadania dos pobres.

Sendo a função precípua da Educação Popular a conscientização, segundo o seu histórico ideário, é fundamental nos acercarmos dessa categoria para que possamos ter a clareza teórica de que conscientização não consiste, messianicamente, na doação da leitura crítica do mundo de alguns poucos iluminados ao povo ou com os grupos populares com os quais trabalham. $\mathrm{Na}$ vertente epistemológica de Paulo Freire encontra-se outra concepção de conscientização que pede uma postura ativa dos oprimidos, de assunção de si mesmos ante as contradições captadas da leitura que fazem da realidade.

A conscientização é isto: tomar posse da realidade; por esta razão, e por causa da radicação utópica que a informa, é um afastamento da realidade. A conscientização produz a desmitologização. É evidente e impressionante, mas os opressores jamais poderão provocar a conscientização para a libertação: como desmitologizar, se eu oprimo? Ao contrário, 
porque sou opressor, tenho a tendência a mistificar a realidade que se dá à captação dos oprimidos, para os quais a captação é feita de maneira mística e não crítica. O trabalho humanizante não poderá ser outro senão o trabalho da desmitificação. Por isso mesmo a conscientização é o olhar mais crítico possível da realidade, que a "desvela" para conhecê-la e para conhecer os mitos que enganam e que ajudam a manter a realidade da estrutura dominante. (FREIRE,1979, pp.15-16).

Então, conscientização é entendida como um processo que implica a ultrapassagem da consciência ingênua da realidade para leitura crítica na qual a realidade se daria como objeto inteligível de análise, onde os homens e as mulheres assumiriam uma posição epistemológica e um compromisso histórico.

Nesse sentido, a conscientização se manifestaria como um teste de realidade, ou seja, quanto maior a conscientização, maior é o desvelamento crítico da realidade. Como compromisso histórico, a conscientização exigiria dos sujeitos que se assumissem como fazedores da história e do mundo, dadas as condições materiais e históricas, numa relação dialética entre consciência e mundo.

Certamente, não podemos pensar numa absoluta homogeneidade de ideias e de ações culturais sob a bandeira da educação ou dos movimentos de vocação popular, embora sejam identificáveis os traços familiares em diferentes tendências que se afirmam nesse campo. As ações empreendidas foram e são matizadas pela presença de diferentes redes culturais e demandas dos grupos sociais - étnicos, religiosos, do campo, das florestas, das cidades, das margens dos rios, etc. - que se munem da Educação Popular para atenderem as suas reivindicações e protagonizarem a construção das mudanças sociais que dão significado profundo à sua práxis. Foi desse modo que a Educação Popular passou a incorporar no seu discurso e na sua ação pedagógica todo um debate político-ideológico construído à margem e, às vezes, na contramão até mesmo daquilo que era produzido na academia.

O ideário da Educação Popular está impregnado, desde a sua origem, da intenção de transformar a cultura popular, simplificada em resíduo da vida comunitária, em movimentos populares reivindicatórios fazedores da história. 
Esse protagonismo popular exigia a conscientização dos sujeitos a respeito das suas condições concretas e históricas, como destacado anteriormente, mediante ações pedagógicas em parceria com a cultura popular, ao mesmo tempo em que essa era o seu ponto de partida. Naturalmente, nas ondas da história essa perspectiva sofreu mutações no seio das múltiplas tendências e experiências que foram sendo gestadas pelos movimentos sociais e suas mais diversas configurações até os dias de hoje.

$\mathrm{Na}$ esteira dos apontamentos para uma crítica saudável a respeito dos limites reflexivos da Educação Popular orientada por formas clássicas de análise de conjuntura social - que por sua vez, não dão conta da complexa teia de fatores que articuladamente produzem a exclusão social - estão Zitkoski (2007) e Brandão (1995), entre outros. Segundo o primeiro, ao observarmos a complexidade do tecido social, a presença da crítica e da abordagem pósmoderna que se instauram ante o esgotamento argumentativo de alguns pilares da racionalidade moderna e as novas configurações da incorrigível lógica do capital em busca da harmonia de seu sócio metabolismo (MÉSZÁROS, 2005) é que se torna forçoso reconhecer que existem inúmeras consequências dessas questões para a organização e atuação prática dos Movimentos Sociais e da Educação Popular.

De acordo com o convite de diálogo da Educação Popular para com a pósmodernidade, teoricamente levado a efeito no texto supramencionado faz-se necessário o exercício de repensarmos a Educação Popular em seus fundamentos teóricos e metodológicos, numa dialógica conexão com o contexto socioeconômico, cultural e político de aceleradas mudanças em curso, provocadas, também, pela materialização do neoliberalismo em diferentes escalas.

Nesse nível de reflexão, a Educação Popular teria como imperativo reorientar-se, porque estamos vivenciando de forma global, na contemporaneidade, progressiva complexificação da vida social sobre a qual os paradigmas tradicionais da análise sociológica não se encontram em condições 
de responderem de modo suficiente. Assim, segundo o autor, a Educação Popular, em seu desafio de revisar a sua ação estratégica necessita observe

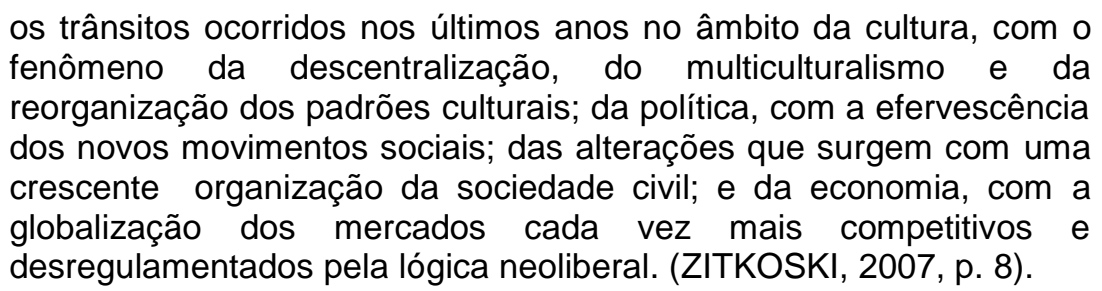

Desse modo, se coloca à Educação Popular o labor de construir novos caminhos teóricos e metodológicos que proponham uma articulação da sociedade civil em sincronia com a complexidade de sua atual configuração. Essa rearticulação da Educação Popular e do tecido social deverá ser o ponto de partida para que a sua perspectiva colabore eficazmente com o processo de democratização dos espaços e bens públicos, bem como, de reorganização dos sistemas políticos e econômicos sob os ditames de uma nova ethos social, não mais definido pelo jogo econômico do capital, mas a favor da humanização dos homens e das mulheres.

Doutro ponto de vista, houve um paradoxo entre expansão dos movimentos de cultura popular e força política na América Latina. Na medida em que cresceu a relação entre intelectuais militantes e os movimentos, ampliou-se o conjunto de novos movimentos sociais vinculados às suas causas específicas, em seus contextos históricos, geográficos e locais, nacionais e étnicos, motivados por uma pluralidade de demandas específicas e, por causa disso, reduziu-se a força desses movimentos quando convergentes em defesa da "causa unitária" da cultura popular.

As principais causas do enfraquecimento desses movimentos residiriam na submissão apressada da cultura à política, na uniformização das diferenças culturais, na oposição entre tradição e modernidade e, finalmente, na contradição polarizante da ideologia para com a questão da identidade. Tais indicativos permitem revisar as matrizes teóricas e metodológicas da Educação Popular na América Latina e repensar a produção de um olhar sobre o tecido 
social que melhor o compreenda, evitando-se análises simplistas e grosseiramente justapostas numa rígida inferência sociológica.

No que diz respeito à submissão da cultura popular à política, o ideário dos movimentos de educação e cultura popular, nos grupos supostamente radicais, revela certo mecanicismo histórico, pretendendo supor que toda e qualquer cultura produzida pelo povo, no âmbito de uma sociedade desigual, como as reinantes na América Latina, seriam inexoravelmente subalternas à cultura das elites dominantes, vindo a reproduzir, pura e simplesmente essa última.

Essa concepção tem sentido, certamente, mas não como uma verdade absoluta, segundo pensavam alguns intelectuais mergulhados nos chamados trabalhos de base, embasados nas matrizes políticas e teóricas em que militaram, sob as quais delineavam suas análises sobre o tecido social. Pensar assim, hoje, consistiria em ignorar a capacidade seletiva, re-criativa e inventiva das culturas tradicionais, tanto quanto, a diversidade sociocultural que há muito vem sendo construída por novos sujeitos sociais que tem se apresentado esfera pública.

No que tange a uma forçada uniformização das diferenças culturais, parece ter estado presente no ideário transformador dalguns militantes da cultura popular uma postura que estabelecia certa opacidade teórica e empírica, que se portava no sentido de enquadrar a cultura popular aos seus referenciais e sob a mesma "causa", ignorando a sociodiversidade da produção cultural. Dessa forma, os teóricos dessa "causa comum" ignoravam os sujeitos sociais que protagonizavam a sua própria história, movendo-se no ambiente de sua identidade cultural específica, destacados da seguinte forma por Carlos $\mathrm{R}$. Brandão:

Novos sujeitos sociais que, sobretudo após se constituírem como movimentos particulares de defesa de direitos humanos, descobrem em si mesmos a evidência de serem também sujeitos de culturas originais. Descobrem por si mesmos a maneira como alguma forma de participação em movimentos sociais atualiza de dentro para fora esta "cultura em processo" que, entre iguais culturas quando olhados desde um ponto de vista mais amplo, abre às portas à possibilidade ampliada de 
afirmação de diferenças culturais de identidade, de ethos, de estilo de vida e mesmo de projeto peculiar de destino social. (BRANDÃO,1995, p. 154)

Outra insuficiência teórica digna de nota é a questão do antagonismo entre tradição e modernidade. Considerando que mesmo a partir dos anos 60 , alguns setores dos movimentos de cultura popular já percebiam que as diferenças da cultura popular são a sua força e sua história, as questões exclusivamente de classe passaram a ser relativizadas perante às problemáticas e às diferenças étnicas, ambientais e culturais. Emergiu daí uma concepção da cultura, que sugere novas práticas de Educação Popular "não-messiânicas" ou modernizantes da cultura popular, menos classificatórias dessa enquanto objeto de análise e de intervenção, buscando, por sua vez, compreender os significados, as diferenças temporais, simbólicas, históricas e circunstanciais dos grupos sociais.

Por fim, outro ponto que assinala o limite de estudos ou experiências no seio da ação pedagógica dos movimentos de cultura popular reporta à oposição entre ideologia identidade. Na defesa da "de ideologização" das culturas populares é provável que se tenha estabelecido ações que, se meditadas de forma desapaixonada, negaram as identidades culturais algumas vezes.

Entendo que toda a prática educativa que se nomeie emancipatória ou que se abrigue nessa perspectiva, deveria favorecer assunção por parte dos educandos de sua identidade cultural e não a sua negação, respeitando e criando um ambiente educativo onde os sujeitos não neguem as suas raízes ou matrizes culturais. Sobre a identidade cultural e a necessidade de sua assunção, Paulo Freire se expressa nesses termos:

Assumir-se como ser social e histórico, como ser pensante, comunicante, transformador, realizador de sonhos, capaz de ter raiva porque capaz de amar. Assumir-se como sujeito porque capaz de reconhecer-se como objeto. A assunção de nós mesmos não significa a exclusão dos outros. É a "outredade" do "não eu", ou do tu, que me faz assumir a radicalidade de meu eu. (FREIRE, 2000, p. 18). 
Resíduos de negação ou de possibilidade de assunção da identidade cultural dos educandos devem ser problematizados e analisados em diálogo com novos referenciais sociológicos e pedagógicos para que possamos colaborar, de alguma forma, com a discussão sobre Educação Popular. Daí a relevância das pesquisas sobre experiências de Educação Popular que discutam suas práticas de forma comprometida socialmente, mas não submissa a esta ou aquela vertente, desapaixonada, muito embora eu assuma a perspectiva da nãoneutralidade científica. Quiçá venhamos a nos propor em ouvir o que os sujeitos alvos de nossas intervenções educativas, militantes e de investigação pensam de nosso trabalho sobre eles mesmos. Seria o bom começo de virada epistemológica para a Educação Popular e para a produção acadêmica sobre seu campo.

\section{Para novas perspectivas...}

Procurei nesse texto desenvolver um exercício de fazer dialogar com a teoria e prática, referenciais estudados e minha empiria no campo de ação investigativa. Minha intencionalidade na escrita também se inclinou a trazer ao diálogo em torno da Educação Popular elementos normalmente esquecidos no trabalho com grupos populares, resíduos da convivência, muitas vezes descartados nas análises militantes ou macro sistêmicas que teimam em estabelecer, através de uma ótica utilitarista, o descaso para com os retalhos do cotidiano, onde realmente se materializam as mudanças sociais que semeiam as nossas utopias e embalam o nosso querer bem pelos espoliados das periferias.

Destaquei palidamente a questão de gênero, subsumida nos discursos de luta do movimento de catadores, como noutros movimentos, que estruturam uma representatividade privilegiadamente masculina e sobre aquelas e aqueles que trabalham no setor de reaproveitamento de resíduos sólidos que não podem ser identificados homogeneamente como catadores, considerando que, como no caso do Galpão em que estou inserido, fazem a triagem apenas, mas se 
identificam como recicladores, num status diferente do catador que transita com seu carrinho na rua e cata nas latas de lixo espalhadas pela urbe.

Quero frisar que os diferentes eles e elas não podem ser postos, para fins de análise sociológica ou de ação educativa - que se pretenda a favor das classes populares - numa massa homogênea apelidada de catadores. Além disso, parece ser fundamental uma sociologia reflexiva que compreenda das questões de gênero no que toca a presença do silenciamento das mulheres a partir de diferentes modos de dominação masculina no espaço de associações que se pretendam cooperativas.

Ao invés de me ocupar numa narrativa e reflexão sobre o trabalho e ações que pareçam traduzir ensaios de emancipação política ou empoderamento, como comumente encontramos nas falas e nos escritos de quem labuta na Educação Popular, voltei-me nesse texto a outros aspectos marcantes do cotidiano do Galpão, que são potencialmente criativos e objetivamente afetivos, denotando que a ação coletiva em grupos populares não se faz apenas com palavras de ordem, em marchas e com bandeiras em punho em prol de reivindicações de projetos políticos mais amplos, às vezes, incorporados em suas falas à força de violência simbólica.

Tenho registrado em minhas inserções na A.R.E. Rubem Berta que os afetos, as partilhas mobilizam as sociabilidades dessas mulheres e de alguns homens mais do que supomos e estabelece laços de confiança de tal forma verdadeiros que permitem a presença do diálogo autêntico entre "eu-e-tu" de forma horizontal e humanizada a, a partir da escuta e da acolhida da outredade do interlocutor.

Tudo isso, não numa assembleia, mas numa simples refeição, num encontro em que o comer junto revela à recusa à desumanização que a exclusão tenta concretizar na vida dessa gente por diferentes meios. Para tanto, aproveitei as contribuições de alguns autores estudados para compreender os dados que emergem da empiria e, ao mesmo tempo, para exercitar uma reflexão mais densa sobre o que estudo, aprendendo a não cair em análises aligeiradas e superficiais onde o dado vale por si. 
Por fim, busquei a reflexão teórica sobre o quefazer da Educação Popular em diálogo com os referenciais teóricos disponíveis e numa retomada de reflexão já posta em movimento em trabalhos anteriores. Desenvolvi minha argumentação no sentido de resgate de ideário da Educação Popular reafirmando o seu compromisso histórico para com a libertação dos oprimidos através da conscientização das situações-limites em que se movem e, igualmente, destacando o papel fundamental do diálogo amoroso nesse processo de humanização libertadora.

Entretanto, não pude deixar de anunciar, com outras vozes, a carência das concepções tradicionais da Educação Popular frente à complexidade social de nosso tempo e, ao mesmo tempo, procurei apontar os elementos dessa crítica saudável que denuncia o esgotamento de uma racionalidade e anuncia possibilidades criativas à Educação Popular se dialogicamente aberta às provocações da pós-modernidade, inserida numa orientação progressista e crítica.

\section{Referências}

BRANDÃO, Carlos Rodrigues. Em campo aberto: escritos sobre educação e cultura popular. São Paulo: Cortez, 1995.

DUSSEL, Enrique. Para uma Ética da Libertação Latino-americana (vol. III). São Paulo: Loyola, 1977.

Método para uma filosofia da libertação: superação analética da dialética hegeliana. Tradução de Jandir João Zanotelli. São Paulo: Loyola, 1986.

Filosofia da Libertação. Petrópolis: Vozes, 2000.

FREIRE, Paulo. Pedagogia da autonomia: saberes necessários à prática educativa. Rio de Janeiro: Paz e Terra, 2000.

Pedagogia do oprimido. 36. Ed. Rio de Janeiro: Paz e Terra, 2003.

Pedagogia da tolerância. Organização e notas de Ana Maria Araújo Freire. São Paulo: Editora UNESP, 2005.

Pedagogia da esperança: um reencontro com a pedagogia do oprimido. Rio de Janeiro: Paz e Terra, 2006. 
STRECK, Danilo. Redin, Euclides. ZITKOSKI, Jaime José. Dicionário Paulo Freire. Belo Horizonte: Autêntica Editora, 2008.

MELUCCI, Alberto. A invenção do presente: movimentos sociais nas sociedades complexas. Petrópolis, RJ: Vozes, 2001.

MÉSZÁROS, Istiván. A educação para além do capital. São Paulo: Boitempo, 2005. SANTOS, Boaventura de Sousa. Um discurso sobre as ciências. 8. ed. Edições Afrontamento. Portugal: Porto, 1996

ZIMMERMAN, Roque. América Latina - o não ser: uma abordagem filosófica a partir de Enrique Dussel. São Paulo: Vozes, 1987.

ZITKOSKI, Jaime José. Horizontes da Refundamentação em Educação Popular: um diálogo entre Freire e Habermas. Frederico Westphalen: EDURI, 2000.

Educação popular e pós-modernidade: um olhar em tempos de incerteza. São Leopoldo/RS: Unisinos - Cadernos IHU. Ano 25. n. 21, 2007. 